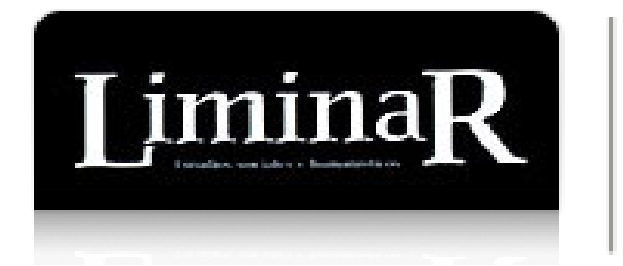

LiminaR. Estudios Sociales y Humanísticos

ISSN: $1665-8027$

liminar.cesmeca@unicach.mx

Centro de Estudios Superiores de México y

Centro América

México

Esponda Jimeno, Víctor Manuel

En la finca el Saúz jurisdicción de Osumacinta, en 9 de noviembre de 1882, veintiocho personas afirmaron ver un círculo que se apareció

LiminaR. Estudios Sociales y Humanísticos, vol. VI, núm. 2, julio-diciembre, 2008, pp. 191-194

Centro de Estudios Superiores de México y Centro América

San Cristóbal de las Casas, México

Disponible en: http://www.redalyc.org/articulo.oa?id=74511194013

- Cómo citar el artículo

- Número completo

- Más información del artículo

- Página de la revista en redalyc.org

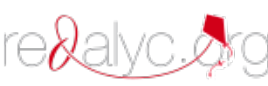

Sistema de Información Científica

Red de Revistas Científicas de América Latina, el Caribe, España y Portugal

Proyecto académico sin fines de lucro, desarrollado bajo la iniciativa de acceso abierto 


\title{
En la finca el Saúz JuRisdicción de Osumacinta, en 9 de NOVIEMBRE DE 1882, VEINTIOCHO PERSONAS AFIRMARON VER UN CÍRCULO QUE SE APARECIÓ
}

\author{
Víctor Manuel Esponda Jimeno
}

\section{Introducción}

L a lectura de este documento conduce de inmediato a dos deducciones prácticas: a) la cuestión de los OvNIS y, b) las apariciones divinas. Con seguridad la primera hoy tiene más peso en razón de que por doquier se ha reportado la presencia de tales objetos; para la segunda es indudable que se trata de un mensaje divino. La orientación escéptica quizá la sitúe como un fenómeno cósmico-meteorológico, o como una simple ilusión óptica producto de una aurora excepcional.

Podemos imaginar qué impresión debió causar la presencia de tal fenómeno en la conciencia y perspectiva de los habitantes de aquellos distantes años, en un lugar apartado y en cierta forma marginado del mundo "urbano" donde la naturaleza es parte sustancial de la cultura y donde el pensamiento racionalista se rige por dogmas de fe impuestas por el prolongado catolicismo que desde finales del siglo XVI se instauró en la zona zoque noroccidental de Chiapas, para cuya orientación

Enviado a dictamen: 06 de agosto de 2008. Aprobación: 06 de octubre de 2008.

Víctor Manuel Esponda Jimeno, investigador del CESMECA-UNICACH, Cuerpo académico: Patrimonio sociocultural. la única e inequívoca explicación de todas las cosas era el origen divino.

El documento es sugestivo por varias razones; nos da cuenta desde un lugar recóndito y en fecha temprana de un fenómeno que en la actualidad ha cobrado notorio interés en varias partes del mundo, este asunto ha generado hipótesis y creencias de todo tipo y por ello se han establecido centros de investigación y documentación, editado revistas y libros, patrocinado programas televisivos, rodado películas, etcétera, todo relacionado con lo extraterrestre y asociado con los objetos voladores no identificados, aún desconocidos, pero frecuentemente reportados e inclusive filmados. Sea cual fuere la explicación que se le dé a tal eclosión, lo que ocurrió en la finca El Saúz es un acontecimiento que seguramente causará regocijo entre los interesados en este tema. Asimismo, la breve información que contiene indica cuán importante era para la gente del campo la opinión y actuación de la iglesia en casi todos los asuntos de la vida social regida por un catolicismo en el que se depositaba toda la confianza y en el que se aceptaba toda explicación no empírica o alejada del entendimiento usual como mandato o indicio celestial, y es precisamente en este orden que gira el contenido de este breve comunicado, escrito con un propósito definido: erigir un santuario. 
En la Finca el SaÚz Jurisdicción de Osumacinta, EN 9 dE

NOVIEMBRE DE 1882, VEINTIOCHO PERSONAS AFIRMARON VER UN CÍRCULO QUE SE APARECIÓ

Documentos

\section{La región}

Esta región es la porción del territorio zoque en que más se ha conservado la cultura de dicha etnia, y por tal motivo se la considera como típica. Los estudios realizados en esta parte son significativos y los sistemáticos se iniciaron durante los cuarenta del siglo XX, en particular los referentes a la lingüística, folklore y religión. Los misioneros protestantes ${ }^{1}$ del Instituto Lingüístico de Verano se internaron en esta región logrando una exitosa labor de proselitismo además de buenos registros en etnografía y lingüística. ${ }^{2}$ Posteriormente ${ }^{3}$ se emprendieron otros estudios que ofrecen una visión de conjunto de la cultura e historia de los pobladores de dicha región.

Esta pequeña finca, establecida en dicha zona, se reporta a finales del XIX que pertenecía a la jurisdicción del partido de Osumacinta y más concretamente a la cabecera San Vicente Ferrer Copainalá, en plena región zoque. Los productos e industrias de los pueblos de esta región lo eran la agricultura de maíz y frijol, hortalizas, cultivo de agave, grana-cochinilla y cañaverales. La distancia entre la finca y Copainalá es de alrededor de 16 kilómetros. Poco se sabe de esta finca y seguramente no era tan antigua pues a diferencia de otras no contaba con ermita. No se dispone de información acerca de ella y lo que se sabe es lo que se presenta en este trabajo.

\section{El documento}

Se halla en los acervos documentales del Archivo Histórico Diocesano de San Cristóbal de Las Casas, en una de las muchas carpetas que existen sin clasificación; la que lo contiene corresponde a "Copainalá-Osumacinta, 1882: zoques”. Está escrito como epístola en caligrafía legible en papel legal. En dicha carta se indica que se acompañaba de un cuadro [dibujo] que ilustraba el modelo del círculo de luces que se apareció, lamentablemente dicha ilustración no se encuentra en el documento y la búsqueda que de ésta hice en dicho archivo fue infructuosa.
En la indicada carpeta hay otros documentos sucintos que tratan sobre acciones que el clero chiapaneco tomó sobre dicho suceso.

El Saúz, noviembre 24 de 1882

\section{Sr. Presbítero Don Vicente Morales}

Muy Señor de mi respeto y cariño

Aunque no tengo el honor de conocerlo pero me tomo la libertad de ponerle ésta con dos objetos; siendo el primero de saludarlo y el segundo manifestarle que el día 9 del presente Noviembre, poco más o menos como a las seis de la mañana, salí de la casa para el patio y al voltear a mirar por el lugar de la tejería, me encontré con la vista del circulo de colores que en medio mostraba un objeto de imagen como el cuadro que le remito.

También para no equivocarme limpié mis ojos y al ver lo positivo llamé a mi familia para que presenciara, como al efecto presenciaron, asimismo fueron llegando varias personas mujeres de los sirvientes de esta finca.

También dice a U. que todos nos atamos, no obstante se tocaron rogaciones y se rezó el Rosario y al salir del rezo ya no había nada; a más de esto también hace a U. presente que temerosos de la enfermedad se comenzó a rezar el Rosario de María Santísima todas las noches a las oraciones y cuyo rezo se comenzó desde el 5 de septiembre y lo continuamos hasta la fecha.

Repite a U. que le remite el cuadrito, modelo poco más o menos del circulo que el nueve del presente vimos en el lugar de la tejería de esta finca y lista de las personas que vieron tal objeto y que dan fe, no firmando porque por casualidad nadie sabe y sólo lo hace el señor don Francisco Hidalgo que es el único que sabe firmar. De lo que se servirá disimular lo mal escrito y dictado de ésta.

Haré a U. presente que con este mismo carácter escribo al señor cura don Joaquín Palacios, pero como ya 
no se encontró, esto es la causa que no sabrá nada, pero le suplico si a bien lo tiene darle una satisfacción en los mismos términos.

Quedando de U. afectísima y segura servidora que besa sus manos.

Valentina Márquez de Vázquez.

\section{Comentario}

Es claro que este documento perseguía un propósito concreto y era el de solicitar ante la autoridad eclesiástica que en dicha finca se erigiera un santuario ${ }^{4} \mathrm{en}$ advocación a María Santísima, La aparición del circulo luminoso se dilucidó por los propietarios y vecinos de la finca como un mensaje divino de la Virgen María. En aquellos vetustos tiempos el fenómeno OVNI aun no se inventaba y por ello se debe descartar que se interpretara como una manifestación extraterrestre o como una acción maléfica. A quien estaba dirigida esa misiva era al cura de Copainalá, que lo era don Vicente Morales, quien al tener conocimiento de su contenido, de inmediato la hizo llegar al obispado para que se proveyera lo conducente y así él se exoneraría, temporalmente, de la responsabilidad que le vendría al comisionarlo para que hiciese las diligencias de veracidad de lo reportado en dicha carta. Según un documento agregado al referido se indica que el "Cuadro contenía la aparición de la Santísima Virgen y que las apariciones había ocurrido los días 13 de diciembre, 3 de noviembre, 2 de diciembre, 8 de diciembre, 12 de diciembre." Y eso era una clara señal de que la Virgen pedía se le construyera santuario. A esta petición respondió el Dr. José Feliciano Lazos, dignidad eclesiástica de Catedral, que para verificar y autenticar el dicho de los peticionarios, comparecieran los testigos a la ciudad de San Cristóbal para jurar sus dichos y que si lo que declaraban era falso pagarían todos los gastos que se generasen durante el proceso. Los testigos respondieron que eran pobres y que no podrían costear siquiera su traslado a dicha ciudad. Por su parte, doña Valentina instruyó de nuevo a Florencio Palacios para que escribiera al señor Provisor del Obispado chiapaneco que, en vista de las limitaciones y carencias, invitaba a quienes correspondiera pasaran a la finca para comprobar los hechos relatados.

Nada se hizo al respecto, y hasta ahí llegó el asunto. Es rasgo casi generalizado que en las sociedades rurales se reporten apariciones divinas y los testigos pretendan que en los lugares de aparición se levanten santuarios que a la postre se convertirán en centros de peregrinaje y en consecuencia de fanatismo, chantaje y engaño para los fieles quienes firmemente convencidos creen que el Sumo Creador les está indicando un camino para la alivio de sus dolencias y salvación de sus almas.

La historia de las apariciones divinas se reporta desde la más remota antigüedad y en todas partes. El aparicionismo en México es un fenómeno psicosocial que debe ser retomado con miras a entender buena parte del ethos, idiosincrasia e identidad nacionales, así como para vislumbrar el manejo político que de estas manifestaciones se ha hecho; el caso de la Virgen de Guadalupe ("aparecida" al indio Juan Diego, hoy convertido en santo) es crucial en la historia y sociología nacional. Para el caso de Chiapas las revelaciones son numerosas y aún siguen sucediéndose. Para ilustrar un poco este asunto, baste mencionar las que acaecieron en 1712 (la visión de María Candelaria, tzeltal de Cancuc) y 1869 (la id de Agustina Gómez Checheb, tzotzil de Chamula), ambas preámbulos de las sublevaciones indígenas más famosas que han habido en Chiapas; pero estas visiones se presentaron a los ojos - o imaginación - de nativos que no se les consideró dignos de tal privilegio y distinción, en consecuencia tales rumores se tomaron por supercherías, idolatrías, etcétera. por tratarse de que el testigo de la aparición era persona común. Cuando las apariciones son reportadas por clérigos o personalidades notables, el asunto cobra otro giro, y desde luego es preciso que peritos en la materia hagan las diligencias estrictas que marca la iglesia católica para testificar y 
EN LA FinCA EL SAÚz JuRISDicción de OSUMACINTA, EN 9 dE NOVIEMBRE DE 1882, VEINTIOCHO PERSONAS AFIRMARON VER UN CÍRCULO QUE SE APARECIÓ

certificar que el fenómeno es auténtico y verdadero, pero se tiene mucha cautela en esto pues de dar como cierta cualquier aparición acarrearía serios contratiempos a la iglesia y, por consiguiente, los santuarios serían ilimitados y no faltarían visionarios que asegurarían que tal santo o virgen se les apareció en determinado objeto o inmueble.

\section{Notas}

${ }^{1}$ La introducción de adventistas, presbiterianos, etc., en dicha zona se llevó a cabo a principios de los años cuarenta del siglo XX, y su mayor actividad se registra entre 1943-1950. De las acciones y recursos para propagar sus cultos, el cura que fue de Copainalá, don Rafael Flores, dio cuenta en sendas cartas que envió al señor Lucio Torreblanca y Tapia, obispo en aquel entonces, así como a monseñor Eduardo Flores Ruiz. (Archivo Histórico Diocesano, San Cristóbal de Las Casas. "Copainalá. II.c. ll.c. Hdas").

${ }^{2}$ Para Copainalá véase los breves textos de William L. Wonderley, "Textos en zoque sobre el concepto de nagual”, en Tlalocan, vol. I, núm. 2, 1946, pp. 97-105; "Textos folklóricos en zoque. Tradiciones acerca de los alrededores de Copainalá, Chiapas", en Revista Mexicana de Estudios antropológicos, núm. 9, 1947, pp. 135-163, y W. Roy Harrison, "The Mason: A zoque text", en Tlalocan, vol. III, núm.3, 1952, pp. 193-205.
${ }^{3}$ Vide Carlos Navarrete, "Fuentes para la historia cultural de los zoques", en Anales de Antropología, 1970, VII, páginas 207-246, Instituto de Investigaciones Antropológicas, Universidad Nacional Autónoma de México. Desde mediados de los ochenta del XX el interés por el estudio de esta etnia se intensificó generándose varias publicaciones dentro de las que se cuentan las memorias de los investigadores de la región zoque ( $I^{a}$. Reunión de investigadores del área zoque, 1986, Centro de Estudios Indígenas, Universidad Autónoma de Chiapas, talleres gráficos UNACH, 1989; Cultura y etnicidad zoque, Universidad Autónoma de Chiapas y Universidad de Ciencias y Artes de Chiapas, Tuxtla Gutiérrez, 1998, y Presencia zoque, Universidad Autónoma de Chiapas, Universidad de Ciencias y Artes de Chiapas y Universidad Nacional Autónoma de México, 2006.

${ }^{4}$ Ya en 1877 el cura de Copainalá, don Manuel de Jesús Rojas, a pedimento y nombre de don Francisco Vázquez, esposo de doña Valentina y propietario de dicha finca, solicitó al gobierno eclesiástico licencia para que se erigiera en dicha finca una capilla bajo el título de Esquipulas, argumentado la necesidad de ésta para el fomento y celebración del Santo Sacramento, aduciendo además que las distancias que mediaban entre este punto y las iglesias más cercanas eran en su mayoría de 4 leguas (Copainalá, Coapilla y Chicoasén). Archivo Histórico Diocesano de San Cristóbal de Las Casas. "Copainalá. II.c. ll.c. Hdas." 